\title{
Cardiac amyloidosis: non-invasive diagnosis
}

\author{
DV Viviane Tiemi Hotta ${ }^{\mathbf{1}, 2}$ \\ Maria Clementina Pinto Giorgi ${ }^{1}$ \\ (i) Fábio Fernandes ${ }^{1}$ \\ (D) Maria Cristina Donadio Abduch ${ }^{1}$ \\ DD Andréa Maria Gomes Marinho Falcão \\ (D) Charles Mady ${ }^{1}$
}

1. Instituto do Coração (InCor), Hospital das Clínicas HCFMUSP, Faculdade de Medicina, Universidade de São Paulo, São Paulo, SP, Brasil. 2. Fleury Medicina e Saúde, São Paulo, SP, Brasil.

http://dx.doi.org/10.1590/1806-9282.66.3.345

\section{SUMMARY}

Cardiac amyloidosis is an infiltrative disease which requires a high degree of clinical suspicion for appropriate diagnosis. Early diagnosis and the definition of the type of amyloidosis play a key role in the early treatment and prognosis of this disease. In this context, the use of cardiac biomarkers such as troponins and NT-proBNT associated with analysis by multimodality imaging methods like echocardiographic techniques such as strain, nuclear medicine, and cardiovascular resonance imaging have an increasing role in patients with cardiac amyloidosis. This article details the role of non-invasive diagnostic methods in patients with cardiac amyloidosis.

KEYWORDS: Amyloidosis. Echocardiography. Magnetic resonance spectroscopy. Nuclear medicine. Biomarkers.

\section{INTRODUCTION}

Amyloidosis is a systemic disease resulting from tissue deposition of an amyloid substance. Although the heart is one of the organs most frequently affected in systemic amyloidosis, cardiac involvement is not a rule. Regardless, it is essential to identify it, since the presence of cardiac amyloidosis (CA) significantly affects the prognosis of the disease ${ }^{1-4}$.

Clinically, it can be classified as:

1. AL amyloidosis is the most severe and common form of systemic amyloidosis. It results from the deposition of protein derived from fragments of the immunoglobulin light chain (AL amyloid). The heart is affected in up to $90 \%$ of the patients, and only $5 \%$ have isolated heart disease ${ }^{4}$.

2. The hereditary amyloidosis (familial) is an autosomal dominant inheritance disease caused by tissue deposition of mutant amyloid protein derived from genetic variants of transthyretin (TTR), apolipoprotein A-I, lysozyme or fibrinogen alpha chain. The heart is most commonly involved with the mutation of TTR (ATTR amyloidosis) 5 .

3. The senile systemic amyloidosis (or wild type) results from the deposition of amyloid proteins derived from wild type transthyretin(TTR wt). It occurs more 
frequently among men with a mean age of 78 years, and its prognosis is better than those of the $\mathrm{AL}$ and ATTR presentations.

4. AA amyloidosis results from the excessive production of a non-immunoglobulin protein known as AA. Kidney disease is frequent in this subtype, while clinically significant involvement of the heart is rare.

This paper details the use of noninvasive methods for the diagnosis of patients with cardiac amyloidosis.

\section{CLINICAL PRESENTATION}

The degree of cardiac involvement is variable and depends on the different types of amyloidosis; it is frequent in senile, AL, and ATTR amyloidosis, but rare in AA amyloidosis. CA includes a subclinical stage characterized by discrete and unspecific symptoms. Patients may present signs of heart failure (HF); however, with preserved ejection fraction (HFpEF) secondary to diastolic dysfunction and increased left ventricular filling pressures ${ }^{6}$.

Orthostatic hypotension occurs in approximately $10 \%$ of patients due to amyloid infiltration into the autonomous nervous system and/or blood vessels. Angina may occur due to amyloid infiltration into the intramyocardial vessels. Syncope is a common symptom secondary to dysautonomia and arrhythmias ${ }^{4-6}$.

The prognosis is related to a particular subtype of cardiac amyloidosis. Senile amyloidosis presents less cardiac involvement and has a good prognosis when compared to ATTR. AL amyloidosis, on the other hand, presents a very reserved prognosis ${ }^{1-6}$.

\section{DIAGNOSIS}

The clinical diagnosis should be suspected in patients with HF symptoms associated with unexplained weight loss, peripheral (such as carpal tunnel syndrome) or autonomic (postural hypotension and syncope) neuropathy, nephrotic syndrome, and hepatomegaly ${ }^{1-6}$.

\section{Electrocardiogram}

The ECG is usually abnormal, and the most characteristic finding is the presence of QRS complexes of low voltage or decreased progression of the $\mathrm{R}$ wave in the precordial derivations (Figure 1A). Low voltage is more common in the AL type and less common in the TTR and senile presentations of the disease. Other findings include the presence of a pseudo infarction pattern, bundle branch blocks, and axis deviation. Among arrhythmias, atrial fibrillation or flutter is common and may be related to atrial amyloid deposition $^{7}$. The presence of low voltage on the ECG has also been associated with a worse prognosis in all types of the disease, including hospitalization, death, or orthotopic heart transplantation ${ }^{8}$.

Symptomatic conduction system disease requiring permanent pacemaker implantation is an uncommon manifestation of cardiac amyloidosis, al-though it is likely that a number of sudden cardiac deaths occurring in patients with amyloidosis may be due to bradyarrhythmias. Isolated conductiondisease appears to be most often associated with senile amyloidosis, although survival after the onset of clinically significant conduction disease was not different in patients with senile amyloidosis when compared with those with primary amyloid-osis. In patients with conduction disease due toprimary amyloidosis in whom the underlying disease cannot be modified, the prognosis is poor ${ }^{9}$.

\section{Biomarkers}

The dosage of serum biomarkers, such as BNP and NT-pro BNP and troponin levels (cTnT or cTnI), allows an early diagnosis of myocardial involvement and its elevation is indicative of a worse prognosis ${ }^{10}$.

Two prognostic models were designed using cutoff values for NT-pro BNP and cTnT or cTnI in patients with the AL presentation ${ }^{10.11}$. Based on their increased levels of troponins and/or BNP, the patients were classified as stage I, II, or III. In stages I, II, and III, the survival rate was $26.4,10.5$, and 3.5 months, respectively. In patients with the ATTR presentation, heart biomarkers were abnormal in a substantial percentage of patients, and BNP/NT-pro BNP were independent predictors of survival ${ }^{10.11}$.

\section{Echocardiography}

There can be thickening of the atrial walls, atrioventricular valves, left ventricular intramural deposition with an increase in the myocardial thickness, signs of diastolic dysfunction, and reduction of longitudinal LV function in a subclinical stage $\mathrm{e}^{12-14}$.

It is important to note that these echocardiographic findings are nonspecific and often absent in early stages, besides being more frequent in the ATTR presentation. Differential diagnoses include hypertrophic cardiomyopathy, aortic valve stenosis, advanced chronic renal insufficiency, and other infiltrative cardiomyopathies. 


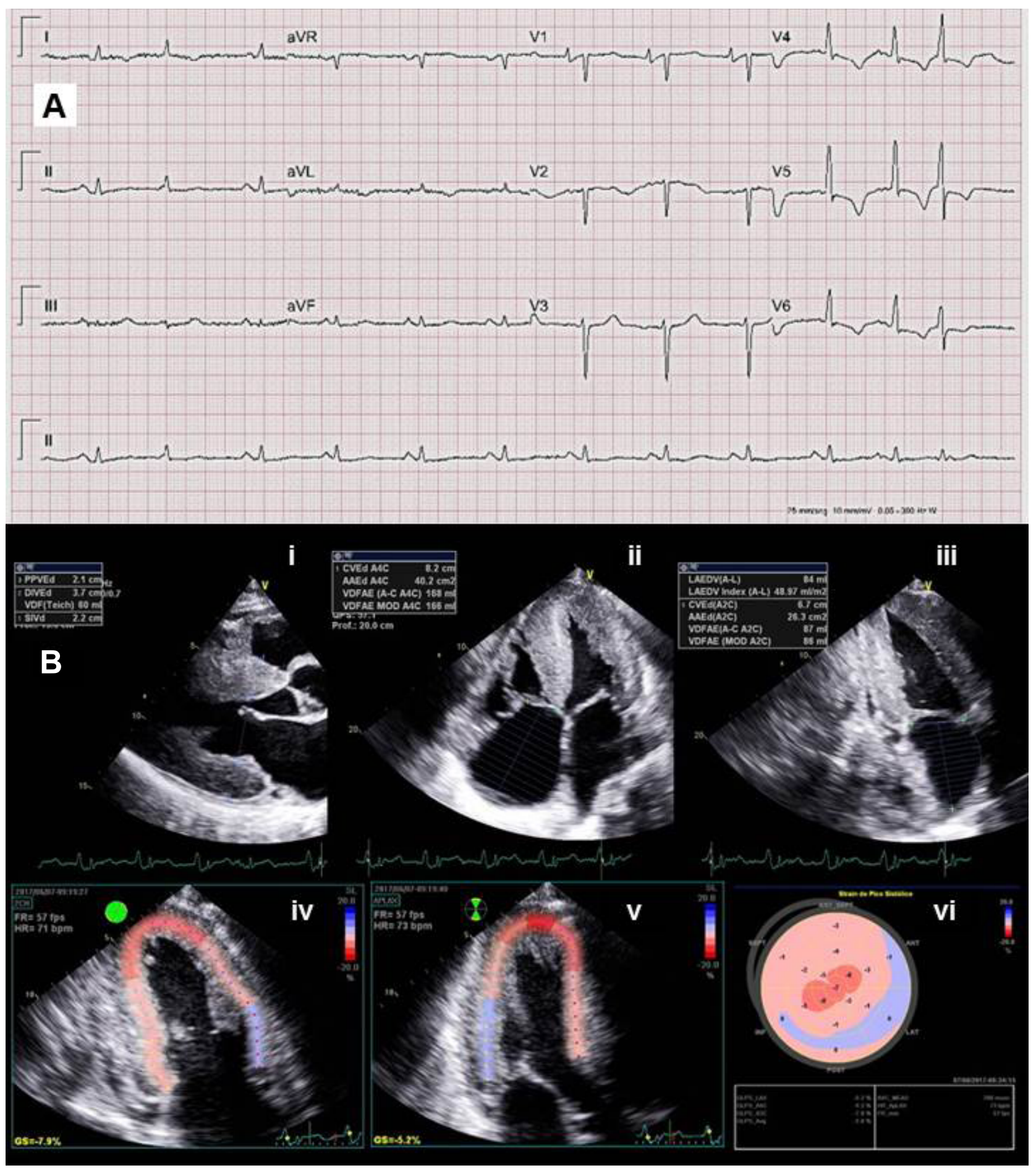

FIGURE 1. A. Electrocardiogram (ECG) of a patient with TTR amyloidosis showing low QRS complex voltage in the frontal plane, in addition to signs of an electrically inactive area in the anterior wall ("pseudo infarction"). B. Typical echocardiographic findings of a patient with AC: thickening of the left ventricular walls with a shiny and granular appearance in parasternal longitudinal view (i), Apical 4-chambers (ii) and Apical 2-Chambers (iii); global and segmental longitudinal myocardial deformation impairment (strain) (iv to vi). There is less involvement of the apical strain in relation to the basal and midsections (apical sparing pattern) (vi).

The progression of the disease causes a significant increase in left ventricular wall thickness $(>15 \mathrm{~mm})$ of granular aspect, resulting in signs and symptoms of HFpEF (Figure 1B) ${ }^{6}$. The presence of a restrictive pattern to the mitral Doppler indicates significant diastolic dysfunction and is indicative of a poor prognosis ${ }^{15}$.

The thickening of the ventricular wall sometimes can be local and may be confused with hypertrophic cardiomyopathy. A recent study showed that $5 \%$ of 
patients with hypertrophic cardiomyopathy had a diagnosis of real TTR amyloidosis ${ }^{16}$.

LVEF is often preserved even in the presence of $\mathrm{HF}$ and in more advanced stages. In some patients, systolic dysfunction can be observed as a result of significant necrosis of cardiomyocytes and extensive fibrosis.

An atrial thrombus can be found, even in the presence of sinus rhythm in patients with AL presentation ${ }^{17}$.

Current echocardiographic techniques, such as the analysis of myocardial deformation (strain) by speckle tracking, also play an important role in patients with cardiac amyloidosis. The evaluation of the longitudinal strain is a sensitive method for the early detection of cardiac amyloidosis before the onset of symptoms and the increase in the myocardial thickness, and it is correlated with the progno$\operatorname{sis}^{18.19}$. The involvement of the LV longitudinal strain is present in different subtypes of amyloidosis, and these abnormalities are correlated with other echocardiographic parameters ${ }^{19}$.

Phelan et al..$^{20}$ described a pattern with relative preservation, or relatively normal values of deformation of the apical segments (apical sparing). The presence of this pattern has prognostic implications; it is a predictor of lower rates of cardiac events(Figure 1B) ${ }^{19}$. This pattern has been useful in the differentiation of cardiac amyloidosis from other causes of LV hypertrophy, such as in patients with aortic stenosis and hypertrophic myocardiopathy.

Recent studies have demonstrated the efficacy of three-dimensional echocardiography in differentiating cardiac amyloidosis from other types of LV hypertrophy ${ }^{21}$. The left atrial function is also often reduced in patients with cardiac amyloidosis, even in patients in sinus rhythm ${ }^{22}$.

Finally, measurements of right ventricular function have also been considered important predictors of prognosis in cardiac amyloidosis ${ }^{23}$.

\section{NUCLEAR MEDICINE}

From the early 1970s, it has been found that some diphosphonates and sodium pyrophosphate derivates labeled with technetium-99m (PYP), which are radiopharmaceutical agents commonly used for bone scintigraphy, may present uptake in the heart and, eventually, in other organs (especially the liver and peripheral muscles) in patients with amyloidosis ${ }^{24}$. In addition to PYP, available in the United States and in Brasil, DPD (3,3-diphosphono-1,2-propanodicarboxylic acid) has been used with similar results in Europe. The mechanism by which the uptake happens is not entirely clear, but it has been found that these substances bind to calcium mainly on areas where this ion is actively deposited.

TTR amyloidosis often presents a higher number of microcalcifications, which could justify the increased uptake of these radiopharmaceutical agents (Figure 2A). The greater microcalcification found in TTR amyloidosis can be explained by the more advanced age of patients and a longer time of disease evolution.

In the absence of cloned immunoglobulins produced by plasma cells, the intense cardiac uptake of PYP is highly suggestive of a TTR presentation; thus, a biopsy may eventually not be necessary for a diagnosis. However, other types of amyloidosis can also present varying degrees of microcalcification and eventually show a small degree of the uptake of these tracer agents.

Using a visual score $(0=$ absence of uptake, $1=$ uptake smaller than the costal arches, $2=$ uptake equal to the costal arches, and 3= high uptake - more intense than bone uptake) for the evaluation of cardiac PYP uptake, it is possible to differentiate between TTR and other types of cardiac amyloidosis ${ }^{25}$.

It is also possible to use a semiquantitative analysis considering the count rate per pixel in the projection of the cardiac area and in the contralateral chest. Values lower than 1: do not suggest ATTR; above 1.5: highly suggestive of ATTR; values between 1 and <1.5: may be associated with AL amyloidosis or early ATTR $^{25}$. Values above 1.6 have been associated with a worse prognosis, regardless of the disease presentation ${ }^{26}$.

Positron emission tomography also allows detecting amyloid deposition in the heart, as occurs in the brain $^{27.28}$. Some substances, such as the florbetapir and florbetaben marked with fluorine-18, are being investigated for this purpose. Due to its characteristics of allowing for better anatomical definition than conventional scintigraphy and absolute quantification of process activity, this technique seems to be promising for cardiac amyloidosis assessment.

\section{Cardiovascular magnetic resonance (CMR)}

CMR provides an accurate evaluation of myocardial mass and thickness, in addition to the differential diagnosis between CA and other cardiomyopathies. However, in patients with proteinuria and renal failure, 


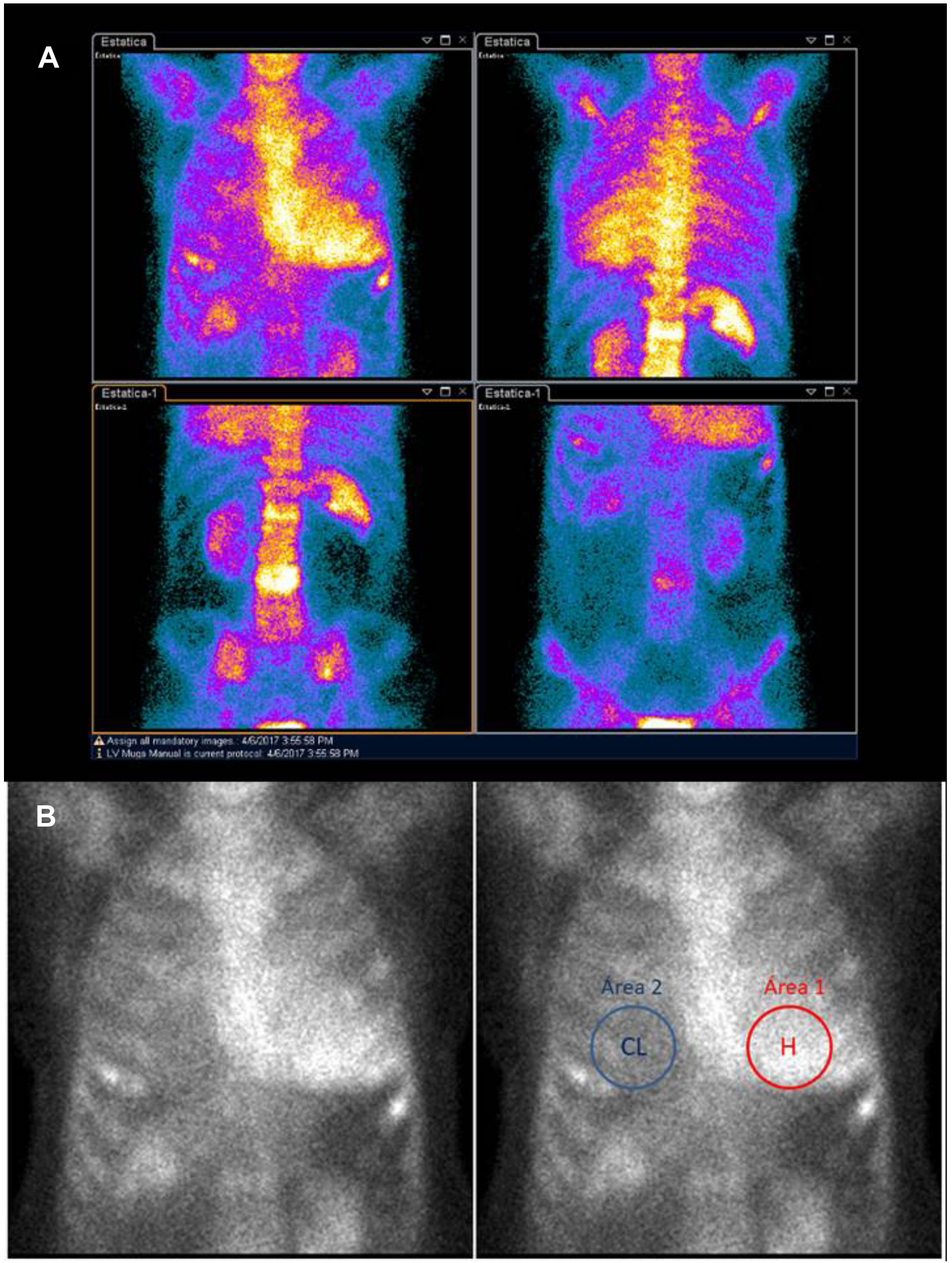

FIGURE 2. A. 85-year-old patient with TTR amyloidosis. The images were acquired three hours after the administration of 20 $\mathrm{mCi}$ of pyrophosphate labelled with technetium $99 \mathrm{~m}$ and show intense increased uptake in the projection of the entire cardiac area. B. Area 1: considers the average counts in the heart area $(H=66.1$ counts per pixel). Area 2: considers the average counts in the contralateral thoracic area $(C L=40.5$ counts per pixel). Heart/contralateral thoracic area ratio $\mathrm{H} / \mathrm{CL}=1.63$. 


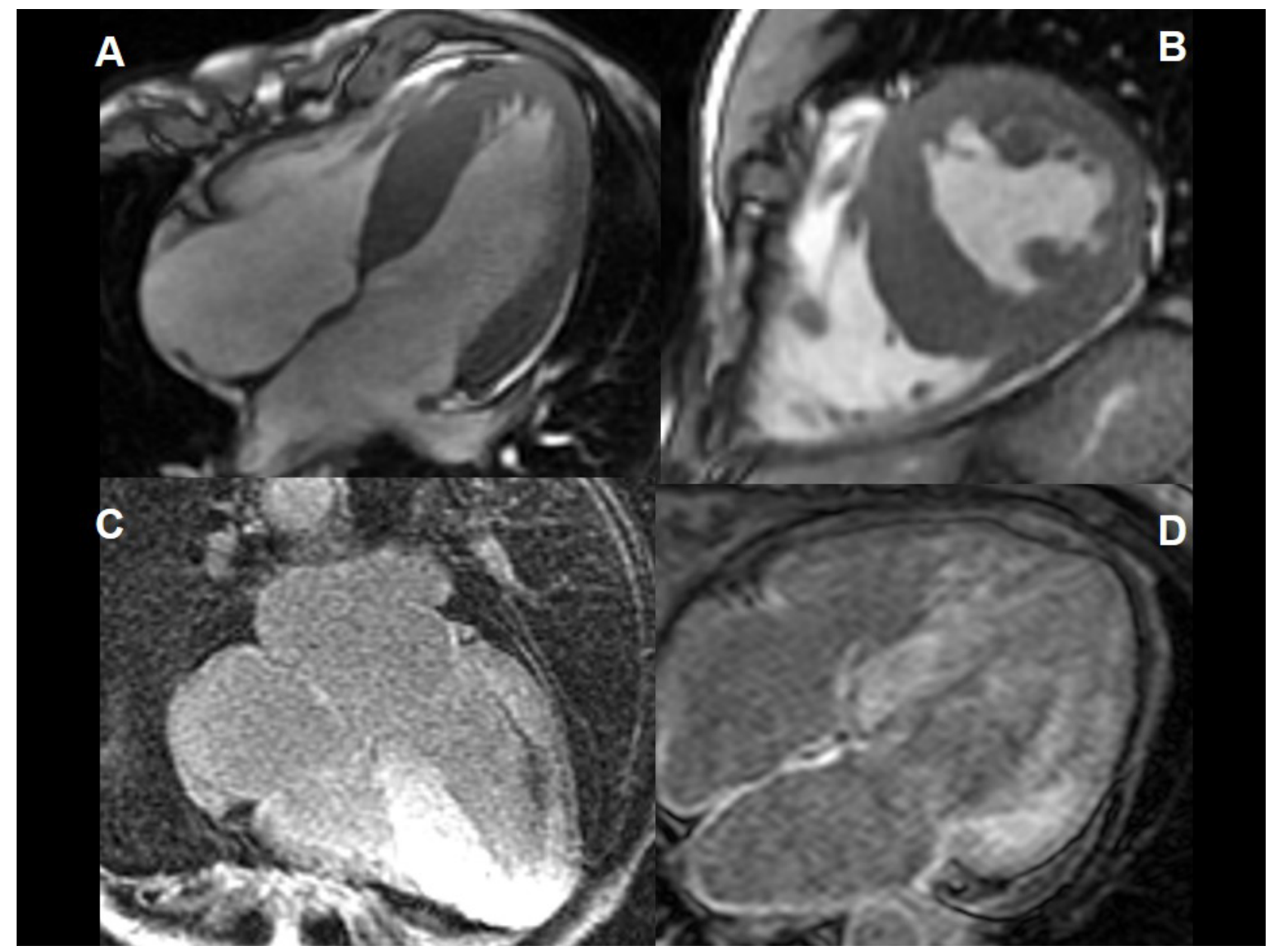

FIGURE 3. CMR images of four chambers $(A)$ and transversal (B), demonstrating an increase in the thickness of the myocardial wall. In $C$ and $D$, the CMR images show late gadolinium enhancement in four chambers. There is a diffuse increase of myocardial signal despite the use of multiple inversion times.

gadolinium injections are contraindicated due to the risk of nephrogenic systemic fibrosis. The sensitivity of CMR for the diagnosis of cardiac amyloidosis is described to be around $80 \%$ with $94 \%$ specificity, according to Takeda et al. ${ }^{29}$.

CMR provides non-invasive information on tissue disease, which has been associated with relevant cardiovascular outcomes. Patients with ATTR and AL amyloidosis present longer values of $\mathrm{T} 1$ consistently when compared to normal volunteers ${ }^{30.31}$ and patients with aortic stenosis ${ }^{32}$. However, despite the great usefulness of T1 mapping, its use alone for CA diagnosis presents some limitations, such as the need for standardization of $\mathrm{T} 1$ mapping acquisition parameters, in addition to the standardization of values between different brands.

Thus, the CMR technique most often used in CA patients consists of analyzing late enhancement (LGE - Late Gadolinium Enhancement). Gadolinium is a contrast agent that migrates rapidly to the extravascular compartment. However, its molecule is too large to penetrate intact cell membranes. Thus, in CA patients, the extracellular volume (ECV) presents progressive expansion due to the deposition of amyloid protein, resulting in a progressively larger reservoir for gadolinium accumulation. In patients with established CA, the ECV often exceeds $40 \%$, a level rarely reached unless in cases of extensive scarring fibrosis ${ }^{33}$. In patients with AL amyloidosis, there is a diffuse subendocardial impairment pattern, while patients with ATTR can present a transmural enhancement pattern (Figure 3$)^{33}$. In addition, delayed enhancement in ATTR saves the apex, which is the same phenomenon that can be observed in the speckle tracking technique, making this finding is suggestive of $\operatorname{ATTR}^{34}$.

A potential incremental diagnostic application can be obtained from the derivation of the respective ECV fractions versus the intracellular volume (ICV). In patients with a definite diagnosis of amyloidosis, calculating the ECV versus the ICV can allow the subclassification into AL or TTR, the latter group 
presenting high cell volumes suggestive of concomitant hypertrophy ${ }^{35}$.

Thus, CMR techniques are very useful in identifying patients with cardiac amyloidosis and those with a high risk of future adverse events. Thus, currently, CMR must be regarded as the first-line preferred diagnostic method to assess patients with cardiac amyloidosis and to differentiate subtypes of cardiac amyloidosis.

\section{CONCLUSIONS}

Cardiac involvement in this disease has been detected with greater frequency in patients with amyloidosis. However, diagnosis is often late, which implies a very reserved prognosis. Although no noninvasive test alone is pathognomonic of cardiac amyloidosis, the use of integrated noninvasive techniques in a context of high clinical suspicion may be enough for proper diagnosis.

\section{RESUMO}

A amiloidose cardíaca é uma doença infiltrativa que exige um alto grau de suspeição clínica para o diagnóstico apropriado. O diagnóstico precoce e a definição do subtipo de amiloidose têm um papel fundamental para a terapêutica e prognóstico desta doença. Nesse contexto, o emprego de biomarcadores cardíacos como as troponinas e NT-proBNT associados à análise por métodos de imagem multimodalidade por técnicas ecocardiográficas atuais como o strain, medicina nuclear e a ressonância magnética cardíaca têm papel crescente em pacientes com amiloidose. Este artigo detalha a utilização dos métodos não invasivos para a avaliação de pacientes com amiloidose cardíaca.

PALAVRAS-CHAVE: Amiloidose. Ecocardiografia. Espectroscopia de ressonância magnética. Medicina nuclear. Biomarcadores.

\section{REFERENCES}

1. Rapezzi C, Merlini G, Quarta CC, Riva L, Longhi S, Leone O, et al. Systemic cardiac amyloidoses: disease profiles and clinical courses of the 3 main types. Circulation. 2009;120(13):1203-12.

2. Wechalekar AD, Gillmore JD, Hawkins PN. Systemic amyloidosis. Lancet. 2016;387(10038):2641-54.

3. Banypersad SM, Moon IC, Whelan C, Hawkins PN, Wechalekar AD. Updates in cardiac amyloidosis: a review. J Am Heart Assoc. 2012;1(2):e000364.

4. Selvanayagam JB, Hawkins PN, Paul B, Myerson SG, Neubauer S. Evaluation and management of the cardiac amyloidosis. J Am Coll Cardiol. 2007;50(22):2101-10

5. Gertz MA, Benson MD, Dyck PJ, Grogan M, Coelho T, Cruz M, et al. Diagnosis, prognosis, and therapy of transthyretin amyloidosis. | Am Coll Cardiol. 2015;66(21):2451-66

6. Mohammed SF, Mirzoyev SA, Edwards WD, Dogan A, Grogan DR, Dunlay $\mathrm{SM}$, et al. Left ventricular amyloid deposition in patients with heart failure and preserved ejection fraction. JACC Heart Fail. 2014;2(2):113-22.

7. Murtagh B, Hammill SC, Gertz MA, Kyle RA, Tajik AJ, Grogan M. Electrocardiographic findings in primary systemic amyloidosis and biopsy-proven cardiac involvement. Am J Cardiol. 2005;95(4):535-7.

8. Cyrille NB, Goldsmith I, Alvarez |, Maurer MS. Prevalence and prognostic significance of low QRS voltage among the three main types of cardiac amyloidosis. Am J Cardiol. 2014;114(7):1089-93.

9. Methew V, Oslo LJ, Gertz MA, Hayes DL. Symptomatic conduction system disease in cardiac amyloidosis. Am J Cardiol. 1997;80(11):1491-2.

10. Dispenzieri A, Gertz MA, Kyle RA, Lacy MQ, Burritt MF, Therneau TM, et al. Serum cardiac troponins and N-terminal pro-brain natriuretic peptide: a staging system for primary systemic amyloidosis. J Clin Oncol. 2004;22(18):3751-7.

11. Kristen AV, Maurer MS, Rapezzi C, Mundayat R, Suhr OB, Damy T, et al; THAOS investigators. Impact of genotype and phenotype on cardiac biomarkers in patients with transthyretin amyloidosis: report from the Transthyretin Amyloidosis Outcome Survey (THAOS). PLoS One. 2017;12(4):e0173086.

12. Dubrey SW, Cha K, Skinner M, LaValley M, Falk RH. Familial and primary (AL) cardiac amyloidosis: echocardiographically similar diseases with distinctly different clinical outcomes. Heart. 1997;78(1):74-82.
13. Siqueira-Filho A, Cunha C, Tajik AJ, Seward |B, Schattenberg TT, Giuliani ER. M-mode and two-dimensional echocardiographic features in cardiac amyloidosis. Circulation. 1981;63(1):188-96.

14. Bellavia D, Abraham TP, Pellikka PA, Al-Zahrani GB, Dispenzieri A, Oh $\mid K$, et al. Detection of left ventricular systolic dysfunction in cardiac amyloidosis with strain rate echocardiography. J Am Soc Echocardiogr. 2007;20(10):1194-202.

15. Klein A, Hatle LK, Taliercio CP, Oh JK, Kyle RA, Gertz MA, et al. Prognostic significance of Doppler measures of diastolic function in cardiac amyloidosis. A Doppler echocardiography study. Circulation. 1991;83(3):808-16.

16. Damy $T$, Costes $B$, Hagège $A A$, Donal $E$, Eicher IC, Slama M, et al. Prevalence and clinical phenotype of hereditary transthyretin amyloid cardiomyopathy in patients with increased left ventricular wall thickness. Eur Heart J. 2016;37(23):1826-34.

17. Feng D, Edwards WD, Oh JK, Chandrasekaran K, Grogan M, Martinez MW, et al. Intracardiac thrombosis and embolism in patients with cardiac amyloidosis. Circulation. 2007;116(21):2420-6.

18. Buss S, Emami M, Mereles D, Korosoglou G, Kristen AV, Voss A, et al. Longitudinal left ventricular function for prediction of survival in systemic light-chain amyloidosis: incremental value compared with clinical biochemical markers. J Am Coll Cardiol. 2012;60(12):1067-76.

19. Ternacle J, Bodez D, Guellich A, Audureau E, Rappeneau S, Lim P, et al. Causes and consequences of longitudinal LV dysfunction assessed by 2D strain echocardiography in cardiac amyloidosis. JACC Cardiovasc Imaging. 2016;9(2):126-38.

20. Phelan D, Collier P, Thavendiranathan P, Popović ZB, Hanna M, Plana JC, et al. Relative apical sparing of longitudinal strain using two-dimensional speckle-tracking echocardiography is both sensitive and specific for the diagnosis of cardiac amyloidosis. Heart. 2012;98(19):1442-8.

21. Baccouche H, Maunz M, Beck T, Gaa E, Banzhaf M, Knayer U, et al. Differentiating cardiac amyloidosis and hypertrophic cardiomyopathy by use of three-dimensional speckle tracking echocardiography. Echocardiography. 2012;29(6):668-77.

22. Modesto KM, Dispenzieri A, Cauduro AS, Lacy M, Khandheria BK, Pellikka PA, et al. Left atrial myopathy in cardiac amyloidosis: implications of novel echocardiographic techniques. Eur Heart J. 2005;26(2):173-9. 
23. Cappelli F, Porciani MC, Bergesio F, Perlini S, Attanà P, Moggi Pig none $A$, et al. Right ventricular function in $A L$ amyloidosis: characteristics and prognostic implication. Eur Heart | Cardiovasc Imaging. 2012;13(5):416-22

24. Perugini E, Guidalotti PL, Salvi F, Cooke RM, Pettinato C, Riva L, et al. Noninvasive etiologic diagnosis of cardiac amyloidosis using 99mTc-3,3-diphosphono-1,2-propanodicarboxylic acid scintigraphy. I Am Coll Cardiol. 2005;46(6):1076-84.

25. Bokhari S, Castaño A, Pozniakoff T, Deslisle S, Latif F, Maurer MS. (99m) Tc-pyrophosphate scintigraphy for differentiating light-chain cardiac amyloidosis from the transthyretin-related familial and senile cardiac amyloidoses. Circ Cardiovasc Imaging. 2013;6(2):195-201.

26. Castano A, Haq M, Narotsky DL, Goldsmith I, Weinberg RL, Morgenstern $\mathrm{R}$, et al. Multicenter study of planar technetium $99 \mathrm{~m}$ pyrophosphate cardiac imaging: predicting survival for patients with ATTR cardiac amyloidosis. JAMA Cardiol. 2016;1(8):880-9.

27. Furukawa K, Ikeda S, Okamura N, Tashiro M, Tomita N, Furumoto S, et al. Cardiac positron-emission tomography images with an amyloid-specific tracer in familial transthyretin-related systemic amyloidosis. Circulation. 2012;125(3):556-7.

28. Wells K, Osborne D, Stuckey A, Wilson S, Wall J, Solomon A. 18F florbetapir PET/CT cardiac amyloid imaging in patients with systemic amyloidosis. Nucl Med. 2013;54(suppl. 2):294.
29. Takeda M, Amano $Y$, Tachi M, Tani H, Mizuno K, Kumita S. MRI differentiation of cardiomyopathy showing left ventricular hypertrophy and heart failure: differentiation between cardiac amyloidosis, hypertrophic cardiomyopathy, and hypertensive heart disease. Jpn | Radiol. 2013;31(10):693-700.

30. Banypersad SM, Fontana M, Maestrini V, Sado DM, Captur G, Petrie A, et al. T1 mapping and survival in systemic light-chain amyloidosis. A study highlighting the role of the MRI-based technique called T1 mapping to identify patients with cardiac amyloidosis. Eur Heart J. 2015;36(4):244-51.

31. Fontana M, Banypersad SM, Treibel TA, Maestrini V, Sado DM, White SK, et al. Native T1 mapping in transthyretin amyloidosis. JACC Cardiovasc Imaging. 2014;7(2):157-65.

32. Karamitsos TD, Piechnik SK, Banypersad SM, Fontana M, Ntusi NB, Ferreira VM, et al. Noncontrast T1 mapping for the diagnosis of cardiac amyloidosis. JACC Cardiovasc Imaging. 2013;6(4):488-97.

33. Banypersad SM, Sado DM, Flett AS, Gibbs SD, Pinney $\mid H$, Maestrini $\bigvee$, et al. Quantification of myocardial extracellular volume fraction in systemic $\mathrm{AL}$ amyloidosis: an equilibrium contrast cardiovascular magnetic resonance study. Circulation Cardiovascular imaging. 2013;6(1):34-9.

34. Dungu IN, Valencia O, Pinney |H, Gibbs SD, Rowczenio D, Gilbertson IA, et al. CMR-based differentiation of AL and ATTR cardiac amyloidosis. JACC Cardiovasc Imaging. 2014;7(2):133-42.

35. Fontana M. Prognosis in cardiac amyloidosis by LGE: ready for prime time? ACC Cardiovasc Imaging. 2016;9(6):687-9. 